\title{
Investigations of an optimal inhaler technique with the use of urinary salbutamol excretion as a measure of relative bioavailability to the lung
}

\author{
M Hindle, D A G Newton, H Chrystyn
}

\begin{abstract}
Background-A simple non-invasive method, in which a urine sample is taken 30 minutes after drug administration, has previously been shown to be a measure of the relative bioavailability of salbutamol to the lungs. This technique has been used to determine an optimal inhaler technique with commercially available metered dose inhalers (MDI).

Methods-Ten healthy subjects were trained in the use of MDIs. Each inhaled $4 \times 100 \mu \mathrm{g}$ salbutamol in a series of experiments to examine the relative bioavailability to the lung after different respiratory manoeuvres. Urine collection intervals were $0-0.5$ hours and $0.5-24$ hours after administration.

Results-There was significantly greater elimination of unchanged salbutamol 30 minutes after administration, indicating a greater relative bioavailability of salbutamol to the lungs after (1) exhaling gently to residual volume rather than to functional residual capacity before inhalation; (2) slow inhalation (10 1/min) compared with fast inhalation ( $50 \mathrm{l} / \mathrm{min})$; (3) breath holding for 10 seconds after inhalation compared with no breath holding.

Conclusions-All patient information leaflets and healthcare personnel should standardise the instructions given to patients and should adopt the inhalation method proposed.
\end{abstract}

(Thorax 1993;48:607-610)

School of Pharmacy, University of

Bradford, Bradford, West Yorkshire

BD7 1DP

$M$ Hindle

H Chrystyn

Chest Clinic, St Luke's

Hospital, Bradford,

West Yorkshire

BD5 0NA

D A G Newton

Reprint requests to: Professor H Chrystyn

Received 22 September 1992

Returned to authors

10 November 1992

Revised version received

27 November 1992

Accepted 30 December 1992

metered dose inhaler (MDI) delivers lungs without the systemic effects of oral or parenteral administration. One of the main causes of therapeutic failure is the patient's inability to use the device correctly. Of all asthmatic patients, even after extensive training, $14 \%$ totally misuse their inhalers. ${ }^{1}$ Incorrect use reduces the therapeutic efficacy of inhaled bronchodilators. ${ }^{2}$ The optimal inhaler technique for the use of MDIs is still unclear, with patient information leaflets produced by manufacturers giving contradictory advice.

Lung bioavailability and bioequivalence studies are difficult to perform because of the low drug plasma concentrations after inhalation, and the difficulty in distinguishing between the inhaled and swallowed fraction of the dose. Studies with radiolabelled Teflon particles inhaled from an MDI have shown that about $10 \%$ of the dose is delivered to the lungs with the remainder being swallowed. ${ }^{3}$ Gamma radiolabelling of the commonly used $\beta$ adrenoceptor agonists has proved difficult. Lung bioavailability studies with terbutaline and the ingestion of charcoal to prevent oral absorption of the drug have also revealed a lung bioavailability of about $10 \%$ of the dose. ${ }^{45}$

We have developed a simple method to evaluate the relative bioavailability of drug to the lung with a conventional MDI. This technique is based on the urinary excretion of salbutamol in the first 30 minutes after inhalation, and differentiates between the relative amounts of the dose swallowed and inhaled. After oral administration of $400 \mu \mathrm{g}$ salbutamol syrup (Ventolin), only negligible amounts of unchanged salbutamol were found in the urine sample taken 30 minutes after administration. In contrast, a significantly larger proportion of the dose was recovered in the same time interval after inhaling from an MDI. The amount of salbutamol eliminated in the urine during the first 30 minutes after inhalation is representative of the fraction of drug delivered to the lungs, and is a measure of the relative bioavailability to the lung. The intrasubject variability was found to be low, with a coefficient of variation of less than $6.4 \% .^{6}$ Furthermore, the total amount of salbutamol and its metabolite-the sulphate ester conjugate-eliminated in the first 24 hours was shown to be representative of the systemic availability (lung and oral absorption). ${ }^{6}$ chodilator locally to its site of action in the

\section{Methods}

Ten healthy non-smoking volunteers consented to take part in a study to examine the relative lung bioavailability of salbutamol after inhalation by the use of different respiratory manoeuvres. Each volunteer was rigorously trained to use the inhaler in the following way. The lungs were emptied as far as was comfortable, the inhaler was placed between the lips, actuated and, at the same time, the subjects breathed in through the mouth taking 5-10 seconds to fully inhale, then 
removed the inhaler, held their breath for 10 seconds, and slowly exhaled. This "normal" inhalation technique and modifications to it were examined.

Manoeuvre 1: "normal" inhalation technique as above-that is, inhalation from residual volume to total lung capacity. This technique was repeated with the following modifications.

Manoeuvre 2: inhalation from functional residual capacity to total lung capacity.

Manoeuvre 3: no inspiratory flow-that is, subjects inhaled to total lung capacity, held their breath and the MDI was actuated, swallowed, then had a drink of water.

Manoeuvre 4: no holding of breath-that is, inhalation followed by a deep exhalation.

Manoeuvre 5: inspiration at a "slow" flow rate (over 5-10 seconds). The "slow" flow rate was calibrated as $10 \mathrm{l} / \mathrm{min}$.

Manoeuvre 6: inspiration at a "fast" flow rate (over less than 3 seconds). The "fast" flow rate was calibrated as $50 \mathrm{l} / \mathrm{min}$.

The rate of inspiration in manoeuvres 5 and 6 was controlled by the Aerosol Inhalation Monitor (Vitalograph Ltd). This allowed an accurate measure of the inspiratory flow rate to be made, unlike the earlier manoeuvres ( 1 and 2). The actuator used with these manoeuvres was supplied with the Aerosol Inhalation Monitor.

Each manoeuvre was repeated four times as volunteers inhaled $4 \times 100 \mu \mathrm{g}$ puffs of salbutamol from a metered dose inhaler (Ventolin, Allen and Hanburys Ltd, UK) with an interval of 30 seconds between each dose. Each technique was assessed on a separate day with seven day washout periods and the order of administration was randomised.

All subjects emptied their bladders before each study dose and urine samples were collected during the time intervals $0-0.5$ hours, and 0.5-24 hours after the dose. All urine samples were stored at $-20^{\circ} \mathrm{C}$ before analysis. The volume of urine passed and the urine $\mathrm{pH}$ was recorded.

A sensitive high performance liquid chromatography method ${ }^{6}$ was used to measure urinary excretion concentrations of unchanged salbutamol and its sulphate ester conjugate ester metabolite. The limit of detection of this assay was previously validated as $50 \mu \mathrm{g} / \mathrm{l}$; typical concentrations of unchanged salbutamol measured 30 minutes after inhalation ranged from 160 to $576 \mu \mathrm{g} / \mathrm{l}$. The coefficient of variation for the interday precision of the assay at a concentration of $300 \mu \mathrm{g} / 1$ was $8 \cdot 2 \%$.

Approval of the University of Bradford Ethics Committee was obtained.

\section{STATISTICS}

The study days were compared with the Wilcoxon signed rank test for paired data; $95 \%$ confidence intervals around the median difference were calculated. The relative bioavailability of salbutamol to the lungs after inhalation with manoeuvre 1 was compared with that obtained after inhalation with manoeuvres 2,3 , and 4 , respectively. The actuator aerosol spray orifice of the Aerosol Inhalation Monitor is different from that of the Ventolin MDI, so only comparison between slow (manoeuvre 5) and fast (manoeuvre 6) inspiration could be made.

\section{Results}

Ten healthy volunteers (five women) with mean (SD) age, weight, and height of $29 \cdot 3$
Figure 1 Individual values of urinary unchanged salbutamol recovery 0.5 hours after inhalation by (A) manoeuvres 1 and 2 (B) manoeuvres 1 and 3 , (C) manoeuvres 1 and 4 (D) manoeuvres 5 and 6.
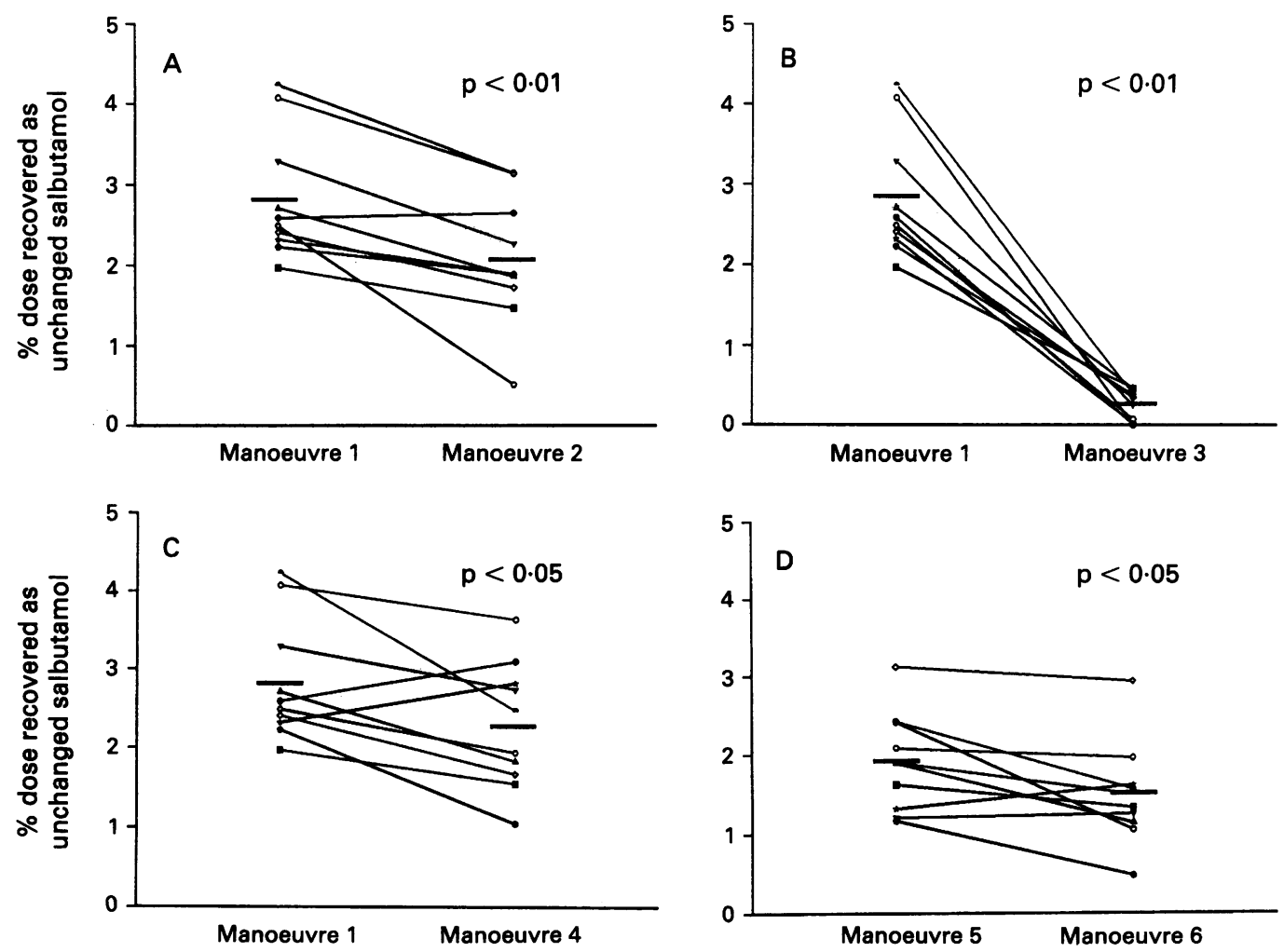
Statistical comparison (Wilcoxon signed rank test) of the urinary excretion of salbutamol 30 minutes after inhalation by the study manoeuvres.

\begin{tabular}{llll}
\hline $\begin{array}{l}\text { Inhalation } \\
\text { manoeuvre }\end{array}$ & $\begin{array}{l}\text { Median } \\
\text { difference (\%) }\end{array}$ & $\begin{array}{l}\text { Confidence } \\
\text { interval }\end{array}$ & $p$ \\
\hline $1 v 2$ & 0.77 & $0.42,2.39$ & $<0.01$ \\
$1 v 3$ & 2.44 & $2.05,3.69$ & $<0.01$ \\
$1 v 4$ & 0.63 & $0.02,1.24$ & $<0.05$ \\
$5 v 6$ & 0.35 & $0.08,0.78$ & $<0.05$ \\
\hline
\end{tabular}

$(7 \cdot 3)$ years, $68 \cdot 3(10 \cdot 7) \mathrm{kg}$, and $1.71(0 \cdot 12)$ metres, respectively, completed the study. Their mean forced expiratory volume in one second $\left(\mathrm{FEV}_{1}\right)$ was $103.4 \%$ of the predicted value. All urine $\mathrm{pH}$ values were in the range $4 \cdot 5-6 \cdot 5$ and, as a result of the polarity and basicity of salbutamol, passive tubular reabsorption in the kidney was negligible.

The results presented in fig $1 \mathrm{~A}$ and the table show that there is a significantly greater elimination of unchanged salbutamol $30 \mathrm{~min}$ utes after administration when inhaling from residual volume (manoeuvre 1) compared with inhaling from functional residual capacity (manoeuvre 2 ). The respective mean (SD) percentage dose recovered as unchanged salbutamol 30 minutes after inhalation was $2.83 \%(0.78 \%)$ and $2.06 \%(0.80 \%) \quad(p<$ $0.01)$. There was no difference in the mean (SD) relative systemic bioavailability after manoeuvres 1 and $2(108 \cdot 1 \%(28 \cdot 2 \%))$.

The mean (SD) proportion of unchanged salbutamol recovered in the urine 30 minutes after actuating the metered dose inhaler into the mouth without inspiration and then swallowing (manoeuvre 3 ) was $0 \cdot 24 \%(0 \cdot 19 \%)$ of the dose, as shown in fig 1B. During the same time interval a significantly greater proportion of the dose was recovered after all inhalation techniques. The extent of the difference compared with manoeuvre 1 is shown in the table ( $p<0.01)$.

Breath holding for 10 seconds after inhalation, as used in manoeuvre 1, significantly increased the percentage recovery of salbutamol in the 30 minute urine sample compared with no breath holding (manoeuvre 4), as shown in fig $1 \mathrm{C}$ and the table $(\mathrm{p}<0.05)$. The mean (SD) recovery 30 minutes after inhalation of salbutamol without breath holding was $2 \cdot 28 \%(0 \cdot 80 \%)$ of the dose. There was no significant difference in relative systemic bioavailability.

The results in fig $1 \mathrm{D}$ and the table reveal that a greater amount of salbutamol was excreted in the first 30 minutes after inhalation at a slow rate (manoeuvre 5) than after a fast inspiration (manoeuvre 6). The mean (SD) percentage of the salbutamol dose recovered 30 minutes after administration following slow and fast inhalation was $1.91 \%$ $(0.64 \%)$ and $1.48 \%(0.65 \%)$, respectively $(\mathrm{p}<0.05)$. There was no difference in the relative systemic bioavailability after inhalation manoeuvres 5 and 6.

\section{Discussion}

Differences in the percentage of the dose recovered in the 30 minute urine sample relate to the efficiency of salbutamol deposition in the lungs after inhalation-that is, the relative bioavailability of salbutamol to the lungs following each manouvre. ${ }^{6}$ The relative systemic bioavailability, derived from the total 24 hour recovery, suggests that the performance of the inhalation technique was equivalent for each study day.

There was a significantly greater relative lung bioavailability after inhalation from residual volume to total lung capacity than from functional residual capacity. Exhalation to residual volume may be counterproductive because of airways collapse, so patients should exhale slowly as far as is comfortable.

Negligible amounts $(0 \cdot 24 \%)$ of salbutamol were delivered to the lungs after actuation of the inhaler without inspiration. A similar value was obtained $(0 \cdot 23 \%)$ after oral administration of $400 \mu \mathrm{g}$ salbutamol syrup to these same volunteers. ${ }^{6}$ The absence of any difference between these values suggests that an inspiratory effort is required to deliver drug to the lungs. These similarities confirm that there is negligible buccal absorption of salbutamol. ${ }^{7}$ The force of the propellant and drug on actuation is insufficient to enter the lungs, showing the need for coordination between actuation of the device and inhalation.

Holding the breath for 10 seconds after inhalation enables particles to be deposited in the peripheral areas of the lungs by sedimentation. The principle of breath holding for as long as is comfortable after inhalation is widely accepted as being essential for improved pulmonary deposition. ${ }^{8}$ We found a significantly greater pulmonary bioavailability after breath holding for 10 seconds than after no breath holding. The presence of significant quantities of salbutamol in the urine sample after no breath holding is a result of the relatively slow inspiration rate aiding deposition.

A greater lung deposition was noted when the inspiration to total lung capacity was slow (over 5-10 seconds). This supports previous findings of better penetration and retention after a slow deep inhalation. ${ }^{910}$ We defined a slow inspiration as taking 5-10 seconds to fully inflate the lungs from a comfortable residual volume state. The closer to 10 seconds, the better the technique.

In common with other lung bioavailability studies, a large intersubject variation (27\% for manoeuvre 1) was seen on each study day, ${ }^{311}$ and our results confirm the findings from previous studies. ${ }^{12}$ Unlike previous studies, we have used commercially available inhalers. The volunteers who took part were rigorously trained for each manoeuvre.

Although the calibre of the airways in volunteers would be different from that in patients with asthma or chronic obstructive airways disease, it is reasonable to suggest that MDI inhalation techniques should be similiar. Patient information leaflets supplied with each manufacturer's product provide conflicting instructions. Since all patient information leaflets supplied by manufacturers and healthcare professionals should be standardised, it is recommended that the 
technique we describe as "normal"-that is, manoeuvre 1-should be universally adopted.

The authors are grateful to the volunteers who took part in this study and to Allen and Hanburys who supplied the Ventolin metered dose inhalers. $\mathrm{MH}$ was in receipt of a Science and Engineering Research Council studentship.

1 Paterson IC, Crompton GK. Use of pressurised aerosols by asthmatic patients. $B M \mathcal{F} 1976$;i:76-7.

2 Orehek J, Gayrard P, Grimaud CH, Charpin J. Patient error in the use of bronchodilator metered aerosols. BMF 1976;i:76.

3 Newman SP, Pavia D, Moren F, Sheahan NF, Clark SW. Deposition of pressurised aerosols in the human respiratory tract. Thorax 1981;36:52-5.

4 Davies DS. The fate of inhaled terbutaline. Eur $\mathcal{f}$ Respir Dis 1984;65(Suppl):141-7.

5 Borgstrom L, Nilsson M. A method for determination of the absolute pulmonary bioavailability of inhaled drugs: the absolute pulmonary bioavailability

6 Hindle M, Chrystyn H. Determination of the relative bioavailability of salbutamol to the lung following inhalation. Brf Clin Pharmacol 1992;34:311-5.

7 Lipworth BJ, Clark RA, Dhillon DP, Moreland TA, Struthers AD, Clark GA, et al. Pharmacokinetics, efficacy and adverse effects of sublingual salbutamol in patients with asthma. Eur $\mathcal{f}$ Clin Pharmacol 1989;37: 567-71.

8 Newman SP, Pavia D, Clark SW. How should a pressurised $\beta$-adrenergic bronchodilator be inhaled? Eur $\mathcal{F}$ Repsir Dis 1981;62:3-21.

9 Palmes ED, Wang CS, Goldring RM, Altoshuler B. Effect of depth of inhalation on aerosol persistence during breath holding. $\mathcal{A}$ Appl Physiol 1973;34:356-60.

10 Pavia D, Thomson ML Shannon HS. Aerosol inhalation and depth of deposition in the human lung. Arch Environ Health 1977;34:131-7.

11 Vidgren MT, Karkkainen A, Karjalainen P, Paronen TP. A novel labelling method for measuring the deposition of drug particles in the respiratory tract. Int $\mathcal{F}$ Pharmacol 1987;37:239-44.

12 Newman SP, Pavia D, Garland N, Clarke SW. Effects of various inhalation modes on deposition of radioactive pressurized aerosols. Eur $\mathcal{f}$ Respir Dis 1982;63(Suppl): 57-65.

\section{Adventitia}

\section{Déjà vu: tuberculosis and AIDS}

Much has been written in the last decade about the fear of occupational infection as a factor in the reluctance of physicians to care for patients with AIDS. The fear of occupational infection was well known to pulmonary physicians who began their careers in the middle of this century, but then the infectious agent was the tubercle bacillus.

Late in 1948, during my final year of training in internal medicine, I made the decision to undertake subspecialty training in pulmonary disease. Soon after it became known in the hospital where I worked that I was going to the Trudeau sanitarium to study, I was approached by a fellow resident who had been treated in the sanitarium for tuberculosis. He tried to convince me that I was very unwise to go to work in a tuberculosis sanitarium because of the high risk of developing the disease.

His response was understandable. The tuberculosis death rate in the USA in 1948 was 48 per 100000 living persons, compared with a rate in 1989 of 0.7 . When tuberculosis was diagnosed in patients who were in general hospitals during that time, prompt isolation and transfer to a sanitarium followed as quickly as possible. Nurses and physicians had limited personal experience with the disease and were fearful of being infected themselves. Although tuberculosis was a definite occupational hazard, patients with undiagnosed disease in general hospitals presented a greater risk than patients in tuberculosis sanitaria who were trained to protect staff.

Treatment options were limited and stays of one to two years in a sanitarium were common. Streptomycin, the first effective drug available for treating the disease, was discovered in 1944. Used in short courses the effects of the drug on symptoms and the chest radiograph were dramatic, but all too often they were shortlived. The emergence of resistant mycobacteria with loss of effectiveness of the drug was frequent. Para-aminosalicylic acid was found to be a weakly effective This column is now open to allcomers for suitable contributions (maximum 700 words). We would like to keep this column running. - SGS antimycobacterial agent in 1946. By 1949 in vitro and animal work, followed by studies in patients with tuberculosis, had confirmed that combined treatment with streptomycin and para-aminosalicylic acid greatly delayed the emergence of streptomycin resistant tubercle bacilli.

In July 1949 I arrived at the Trudeau sanitarium in Saranac Lake, New York, with my wife who was three months pregnant with our first child. The first question I was asked was: "Where and when did you cure?" When I answered that I had not had tuberculosis the follow up question was: "Oh, then your wife must have cured." It was then that I learned that most pulmonary physicians and thoracic surgeons at that time had themselves had tuberculosis. Small wonder that the sanitarium director was shocked to find that my wife was pregnant.

The introduction of isoniazid as an antituberculosis agent in 1954 ushered in the modern era of effective chemotherapy of tuberculosis. Within a few years mortality and morbidity decreased dramatically, and the fear of tuberculosis as an occupational hazard for healthcare givers faded.

The emergence of AIDS in 1981, followed later in the decade by a rising incidence of tuberculosis and the emergence of multiresistant strains of $M$ tuberculosis, changed the complacency of nurses and physicians regarding the risks of on-the-job infection. As had been true when I started in pulmonology, the possibility of exposure to microorganisms for which there was ineffective treatment made the taking of appropriate precautions a part of the day's work. Once again physicians were dealing with a disease that commonly kills young people, and for which treatment is relatively ineffective. In the words of Yogi Berra, the great catcher for the New York Yankees baseball team: "It was déjà vu all over again."

GORDON L SNIDER 